
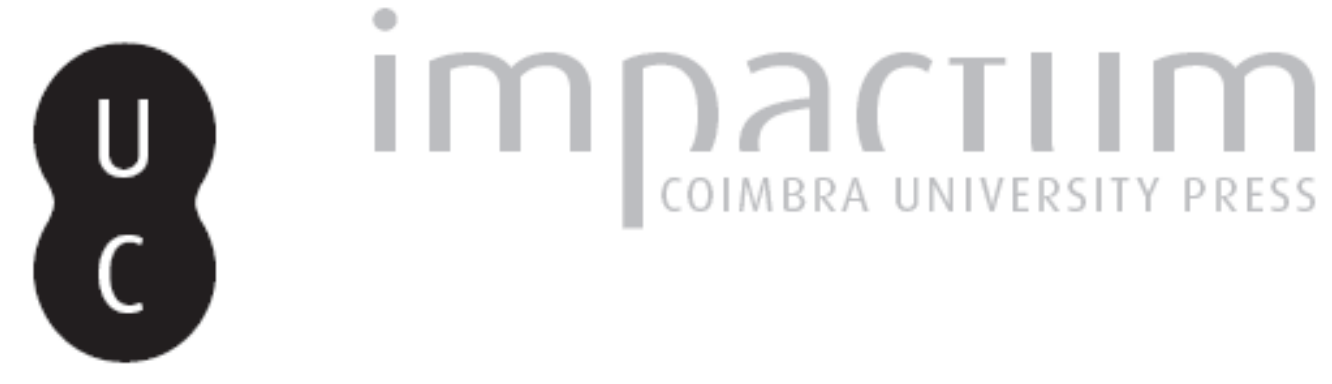

\title{
(Des)figuração do substrato memorável florentino nos poemas David e Como um pombo... de António Osório
}

Autor(es): $\quad$ Silva, Regina Célia Pereira da

Publicado por: Imprensa da Universidade de Coimbra

URL persistente:

URI:http://hdl.handle.net/10316.2/42496

DOI:

DOI:https://doi.org/10.14195/0870-8584_7_3

Accessed : $\quad$ 26-Apr-2023 08:54:05

A navegação consulta e descarregamento dos títulos inseridos nas Bibliotecas Digitais UC Digitalis, UC Pombalina e UC Impactum, pressupõem a aceitação plena e sem reservas dos Termos e Condições de Uso destas Bibliotecas Digitais, disponíveis em https://digitalis.uc.pt/pt-pt/termos.

Conforme exposto nos referidos Termos e Condições de Uso, o descarregamento de títulos de acesso restrito requer uma licença válida de autorização devendo o utilizador aceder ao(s) documento(s) a partir de um endereço de IP da instituição detentora da supramencionada licença.

Ao utilizador é apenas permitido o descarregamento para uso pessoal, pelo que o emprego do(s) título(s) descarregado(s) para outro fim, designadamente comercial, carece de autorização do respetivo autor ou editor da obra.

Na medida em que todas as obras da UC Digitalis se encontram protegidas pelo Código do Direito de Autor e Direitos Conexos e demais legislação aplicável, toda a cópia, parcial ou total, deste documento, nos casos em que é legalmente admitida, deverá conter ou fazer-se acompanhar por este aviso.

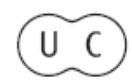




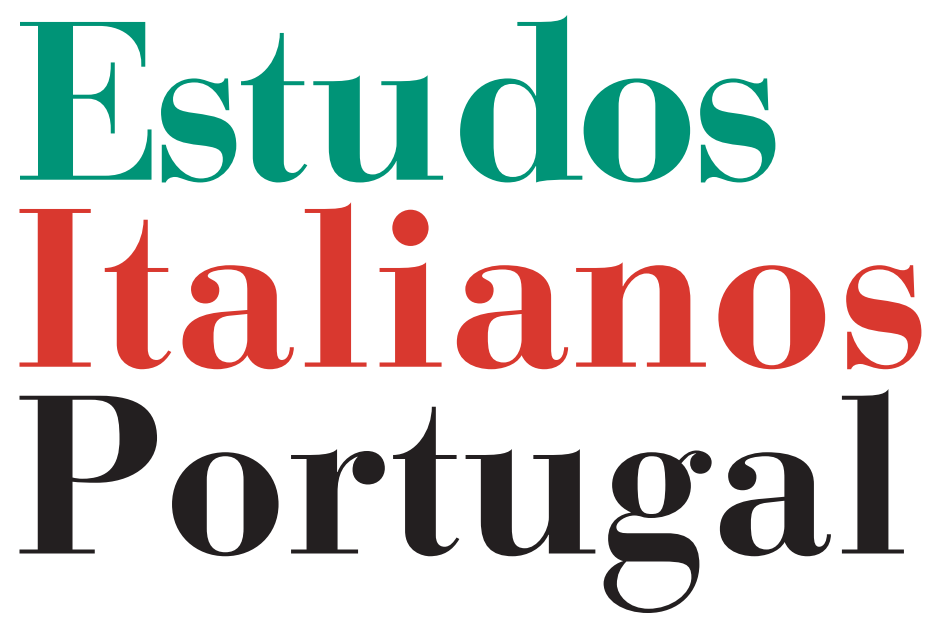

Instituto

Italiano

de Cultura

de Lisboa

Nova Série

$\mathbf{N}^{\mathbf{0}} 7$

2012 
(DES) FIGURAÇÃO DO SUBSTRATO

MEMORÁVEL FLORENTINO

NOS POEMAS DAVID E COMO UM POMBO...

DE ANTÓNIO OSÓRIO

Regina Célia Pereira da Silva

A escritura poética de António Osório apresenta elementos específicos que a diferenciam da arte lírica contemporânea portuguesa. Conscientemente o poeta não submete o texto a uma simples funcionalidade linguística mas

... preferisce asservire la scrittura a un discorso esistenziale ed etico spesso straripante ${ }^{1}$.

Por outro lado, a convivência de aspectos culturais italianos e portugueses na mesma composição lírica, fruto da sua formação pessoal, revela a presença de um bilinguismo que o próprio poeta escolheu ignorar ${ }^{2}$. Pertencer a duas naçōes, ter duas pátrias, duas culturas, falar duas línguas pode, no

* Regina Célia Pereira da Silva é Docente de Língua e Cultura Portuguesas na Università degli Studi l'Orientale e na Università degli Studi "Suor Orsola Benincasa" de Nápoles. Doutoramento em 'Letterature moderne e studi filologico-linguistici', com a tese Le prime opere letterarie luso-indiane e l'identità culturale di Goa (1510-1715) na Facoltà di Lettere da Università degli Studi di Palermo.

${ }^{1}$ António Osório (a cura di C. V. Cattaneo), Decima Aurora, Roma, Edizioni Florida, 1986, p. 5.

${ }^{2}$ Cf. ib., p. 97. 
entanto, caracterizar uma existência de modo dramático ou ser considerada uma riqueza. A este respeito afirma António Osório:

Non è bello avere due patrie, posso garantirlo. L'ultima volta che siamo stati insieme in Toscana, la mamma si metteva improvvisamente a parlare in portoghese, o stroppiava alla portoghese il suo italiano. Ed io avevo nostalgia del Portogallo, e qui ho sete d'Italia. (...) Il rimorso è questo: essere naturalmente doppio, imperfetto, e non aver colpa d'essermi sempre sentito differente. ${ }^{3}$

Os conteúdos abordados e narrados nos seus poemas são absolutamente convencionais ${ }^{4}$ e não se filiam em nenhuma corrente literária, o que consente ao poeta uma grande liberdade de expressão linguística, filológica e de género. Assim, o discurso criativo poético reflecte de maneira real, pura e original, sem recorrer a qualquer tipo de subterfúgio, a refinada formação cultural e literária do autor. É neste sentido que:

... no seu modo mansamente inovador apetecidamente lento e meticuloso, no seu progredir musicalmente inventariante, no seu fascinante realismo mítico, aladamente terrestre e distancialmente afetuoso, [representa] uma das vozes mais fortes, mais isoladas 5 .

Todavia a arte poética é a expressão visível da procura íntima e oculta de respostas para o conhecimento do eu e do nosso estar no mundo. Por isso, o texto poético é frequentemente mensageiro do tempo passado e companheiro dos dias futuros alimentando-se de recordações, sentimentos, emoções e penetrando no desconhecido das percepçóes humanas.

${ }^{3}$ Ib., pp. 97-99.

${ }^{4}$ Cf. J. Manuel Magalhães, Prefácio, O lugar do amor e Décima Aurora, Lisboa, Gótica, 2001, p. 141.

5 E. Lisboa, Amada cal de palavras, A. Osório, "A ignorância da morte", Porto, Editorial Presença, 1982, p. 13. 
Interpretar e analisar a linguagem exclusiva e a estrutura poética das duas composiçôes líricas de António Osório, $D a-$ $v^{v i d}{ }^{6}$ e Como um pombo... ${ }^{7}$, procurando compreender o cunho da pura inspiração intrínseca ao poeta, constitui a finalidade do presente estudo.

Os poemas de António Osório transportam em si mesmos um forte desejo de renascer e de redescobrir a vida regressando ao ponto primitivo não só no sentido individual mas alargando-se à humanidade. Usando uma linguagem clara, rica e decidida, o poeta exprime o seu sentir mais profundo recordando-o e relacionando-o com um momento/instante passado. É a memória que se movimenta. Porquê a memória? Certamente não se trata de uma questão saudosa ou de um simples modo de recordar 'bons tempos passados' mas de realizar o desejo de identificar determinados momentos da vida que facilitam o reconhecimento da tipologia de cenas, sonhos e esperanças que moram na mente e no imaginário de quem, apesar das problemáticas sociais de um mundo global, procura a Beleza e a Serenidade. No acto da redacção o poeta procura a sinceridade, a frescura da naturalidade, a inocência da infância. Voltar à infância significa pois um início e não um fim. Este tipo de escritura não vive de oratória nem transgride. Observa o "real" assim como é, tal e qual é e aparece aos olhos humanos. É por isso que o tal "real" constitui de forma inequívoca o tema, o conceito principal narrado no texto. No entanto, o 'real' revela-se através de vários registos históricos, sociais ou culturais onde o dia-a-dia é o personagem principal e a consciência ética se encontra intimamente ligada à concretização da estética. Neste âmbito, a utilização de determinado léxico não é deixado absolutamente ao acaso e o desejo de ser universal, acolhendo toda a humanidade,

${ }^{6}$ António Osório, Libertação da peste, Lisboa, Gótica, 2002, pp. 100-101.

${ }^{7}$ Carlos Nejar, Revista Brasileira, 60, Poesia estrangeira, fase VII, S.P., 2009, pp. 300-301. 
obriga o escritor a uma escolha decidida e bem motivada da própria terminologia. Em Osório, portanto, encontramos uma conexão tripartida entre o eu, o quotidiano e a linguagem. A visão do espaço real ou imaginário representa uma questão cultural e/ou histórica determinada e alimenta a lírica do poeta. Esse vínculo é ainda mais evidente no diálogo que ele estabelece, frequentemente, entre a poesia e a pintura.

Ora a interpretação e descrição de um determinado espaço, quer seja um território real ou imaginário (simbólico), representa sem dúvida a configuração ou desfiguração da própria identidade. Tenha-se presente no entanto que na linguagem poética, muitas vezes, o eu-poeta que fala é na realidade um outro, criando-se assim um espaço livre que pode ser ocupado por qualquer pessoa que se identifique com a experiência vivida. De facto, o crítico francês Michel Collot afirma que o poeta se póe à escuta do silêncio para entender o eco impercetível de um apelo que, já por si, é inacessível ${ }^{8}$. A linguagem poética tem consciência da impossibilidade de revelar fielmente o real apesar da tensão constante em o querer reproduzir, fraccionar ou decifrar.

Os poemas David e Como um pombo... de forma extremamente evidente, clara e sem qualquer tipo de ambiguidade, transmitem a percepção directa que o poeta tem do património histórico e cultural florentino, o que pressupõe a sua presença física na cidade toscana. Estes dois poemas foram realizados e publicados em dois momentos cronológicos diferentes mas ambos apresentam um único denominador comum: a beleza do património artístico florentino. São poemas constituídos por um léxico muito simples e intenso que não é absolutamente satírico mas que se encontra impregnado de indignação e de uma forte emoção. As próprias palavras deixam transparecer e até extravasam os sentimentos

${ }^{8}$ Cf. M. Collot (dir.), La poésie moderne et la structure d'horizon, Paris, PUF, 1989, pp. 161-162. 
mais íntimos do poeta. Na realidade, tal é o seu desejo pois declara:

Procuro que a minha poesia não seja sentimentalista mas sim plena de emoçôes. Falo de emoçōes porque é o amor pelo outro, pelo mundo, liberto das contingências pessoais; (...)

Tenho uma ligação e uma admiração pela minha mãe... ${ }^{9}$

António Osório dedica numerosos textos à recordação e à memória dos próprios afectos, é o que acontece no volume intitulado A ignorância da morte (1978) o qual apresenta uma inteira secção dedicada às lembranças da mãe e da sua família italiana. O mesmo se verifica no livro Décima Aurora (1982), por exemplo, com o poema $A$ terra prometida no qual

revive memórias de uma viagem por mar a Itália a fim de conhecer a família da Mãe, em Florença. Certos nomes, localidades e episódios são coloridos com a magia e um avassalador sentido de aventura. ${ }^{10}$

$\mathrm{Na}$ realidade, encontra-se patente uma vontade expressa de querer fazer reviver a memória hoje, quer seja ela individual quer seja colectiva. Transporta e reintegra no tecido social antigos sentimentos já esquecidos e sepultados na história passada. Este elemento está muito presente, por exemplo, no volume Décima Aurora. Portanto, as composiçôes líricas que compõem estes volumes não escondem nem mimetizam os sentimentos do poeta, antes pelo contrário, através duma leitura atenta e agradável, o leitor pode identificar ou até identificar-se com as reais sensações, paixões e emoções expressas.

O poeta escreve palavras cheias que ocupam completamente o espaço narrativo e iluminam experiências do passado que

\footnotetext{
${ }^{9}$ Entrevista feita a António Osório por Maria Augusta Silva, Lisboa, Outubro de 2004.

${ }^{10}$ Giovanni Pontiero, "A circum-navegação de enigmas na Décima Aurora de António Osório“, Colóquio/Letras, 82, 1984, p. 43.
} 
se somam às vivências espaciais do presente traduzidas na observação realística e actual de homens, animais, monumentos, praças e ruas. Assim, quer o poema Como um pombo... quer David apresentam como tema central elementos específicos reais do património cultural e artístico presente na cidade natal da mãe do poeta e transmitem imediatamente ao leitor a bio-relação existente entre o eu-poeta e o tecido urbano-artístico toscano.

Outro aspecto importante refere-se ao elemento estético abundantemente presente nas obras de António Osório. O leitor foi habituado desde sempre pelo poeta a uma verdadeira simbiose existente entre as palavras do texto e a pintura, contudo nestas duas composições, o seu discurso é dirigido intencionalmente para a arte escultórica, arquitectónica e monumental toscana. Senão vejamos, a viagem do pombo começa no Piazzale di Michelangelo de Florença. Ao centro desta praça encontra-se a estátua de David realizada por Michelangelo (entrecruzamos assim os dois poemas):

Era o seu David

ficaria

no coração de Florença.

Perfeito como um deus solar. ${ }^{11}$

Na poesia Como um pombo... a identificação do eu-poeta com a ave pombo é fundamental para a eficácia do desenvolvimento estrutural e lexical dos versos. Voando sobre o céu florentino observa toda a cidade tendo a oportunidade de percorrê-la calcorreando-a e captando ares familiares:

... voo, rua a rua, no céu de Florença.

Procuro chegar ao telhado

à destruída casa de teus pais.

Ficou no ar um pouco, que sorvo,

de amor e angústia. (... $)^{12}$

${ }^{11}$ David, cit. 2002, pp. 100-101.

${ }^{12}$ Osório, Como um pombo...., in Nejar, pp. 300-301. 
A cidade de Florença constitui, pois, um símbolo singular que une o passado (materno) com o presente (eu-poeta). Assim e como afirma Paul Mann ${ }^{13}$, o símbolo solicita a capacidade de uma identidade ou de uma identificação. O símbolo recorda a experiência feita (passado) absorvendo o seu sentido mais doloroso no âmago mais escuro, profundo e pessoal, isto é, a intimidade do eu.

Não se esqueça ainda que a cidade florentina no imaginário colectivo português é sinónimo de bom gosto, de civilização ocidental, de Renascimento. Seguindo esta perspectiva, António Osório vai descrevê-la salientando frequentemente as suas características singulares, isto é, como cidade das artes e das letras humanísticas ${ }^{14}$.

$\mathrm{Na}$ sua viagem real ou imaginária pela Praça de Michelangelo observa a estátua de David.

Utilizando uma linguagem simples e directa descreve o acto escultórico criando, como é sua característica, uma delicada conexão entre a arte, o artista e a expressão poética. A leitura do poema acompanha pouco a pouco a realização progressiva de David. Primeiro existe a matéria-prima bruta:
Um bloco
esguio
de mármore,
alto cinco metros.

Percorre depois a criação da cabeça, dos olhos, da boca e do corpo até chegar aos pés. A mão do artista era de tal maneira perfeita (visto que outros não tinham conseguido trabalhar um bloco de mármore assim tão alto ${ }^{15}$ ) que criou:

${ }^{13}$ Cf. Paul de Man, A retórica da temporalidade, "O ponto de vista da cegueira", trad. de Miguel Tamen, Lisboa, Cotovia, 1999.

${ }^{14}$ Cf. Piero Ceccuci (a cura di), Fiorenza mia...! Firenze e dintorni nella poesia portoghese d'oggi, Firenze, University Press, 2009.

${ }^{15}$ Cf. Antonio Natali, Il David di Michelangelo, Ministero dei Beni Culturali, Polo Museale Fiorentino, Firenze, 2009. Segundo fontes do Ministero dei Beni Culturali 
.... ma mais digna

Serena e enérgica

celebração

que o homem

fez jamais de si mesmo.

O roteiro florentino do pombo continua e sobrevoa delicadamente os ex-libris florentinos como por exemplo o Campanile de Giotto, o complexo arquitectónico do Battistero e a cabeça de São Giorgio. Os elementos naturais como a natureza, a água, o rio e as colinas transformam-se em matéria poética, sem alegorias, pois nas águas da corrente límpida do rio Arno se misturaram as dores da sua mãe, as quais são objecto de procura tenaz por parte do poeta como forma de conforto e da tão desejada proximidade maternal. E declama:

[...] Bebo no Arno

a tua última lágrima, igual

à matéria do rio. Chego ao ponto

mais alto do Campanile de Giotto e ouço

os sinos que percorrem Fiesole, as colinas

e casas colónicas. [...]

Prossegue então a sua digressão e não resiste ao input provocado pela componente italiana da sua cultura, cita três inigualáveis artistas florentinos que constituem não só parte da sua bagagem pessoal mas são imprescindíveis para qualquer tipo de estudo literário. Refere o escritor e poeta Dante Ali-

Italiano, em 1464 a escultura de David tinha sido entregue a Agostino di Duccio que abandonou a obra. Assim, foi novamente confiada em 1476 ao escultor Antonio Rosselino que a deixou extremamente incompleta. Em 1501, Michelangelo continua o trabalho destes dois escultores terminando a estátua de David chamada il gigante ( 5 metros). Por vontade do artista, David foi representado com a sua nudez e sem a cabeça de Golia exatamente para representar simplesmente a sua força. Tais elementos históricos foram colhidos e registados de maneira incisiva e transparente por António Osório no seu poema David. 
ghieri, a quem dedicou outros poemas ${ }^{16}$, no entanto, neste caso relaciona-o com o edifício do Battistero onde o poeta foi baptizado. O Battistero é dedicado a $S$. João Baptista padroeiro de Florença e encontra-se num local central da cidade, entre a Piazza del Duomo e Piazza S. Giovanni em frente da catedral de Santa Maria del Fiore e entre a Catedral e a Cúria do Arcebispado, centro religioso florentino. Prossegue depois a sua viagem na arte e cultura florentina falando de um dos fundadores do Renascimento, o grande artista Donatello que com o génio e arte deu um grande impulso à regeneração dos estilos escultóricos dos seu tempo, criando um expressionismo novo bem representado nas suas obras. Conhecendo bem a obra deste artista, Osório não deixa de a referir e realça o seu tecnicismo original e a sua notável concepção e reprodução da beleza:

e conspurco em Orsanmichele a cabeça de San Giorgio tocando no bronze que teve a mão de Donatello.

É notável que apenas com a leitura de dois versos, extremamente expressivos, o leitor consiga entrever ou imaginar a "realeza" da cabeça de S. Giorgio, sem a ver, pois a utilização do verbo 'conspurcar' garante ao verso uma força poética única descrevendo, por si só, a riqueza e pureza intrínseca à obra centenária de Donatello. Para o poeta, o simples toque de uma mão estranha contamina e corrompe a obra. É sagrada. Na realidade, trata-se de uma escultura que faz parte do grupo escultórico encomendado a Donatello e que se encontra na região de Florença, na Chiesa di Orsanmichele também denominada como San Michele in Orto. Donatello trabalhou na decoração dos nichos desta igreja desde 1411 e de modo especial as estátuas de S. Marco e de S. Giorgio que pela sua postura transmitem de certa maneira uma impressão

\footnotetext{
${ }^{16}$ Ver os poemas Modéstia de Dante; Dante.
} 
de querer de um momento para o outro tomar vida e começar a mover-se. De facto, é esta a característica mais apreciada nas obras de arte de Donatello, isto é, a falta de rigidez nas figuras artísticas, a capacidade de dar humanidade e vontade de viver que ele incutia aos olhares das suas esculturas (extremamente expressivo em S. Giorgio).

Voltando a Osório, que não tem pretensões de ser historicamente rigoroso, a grandeza de Leonardo Da Vinci é chamada a participar activamente no génio poético:

[...] Leonardo

comprava no Mercato de San Lorenzo

aves para lhes dar, de novo, asas.

A relação de Leonardo com o Mercato de San Lorenzo é simultaneamente real e irreal pois trata-se de uma espécie de feira onde actualmente se podem encontrar vários produtos que vão desde pronto-a-vestir, às peles e couros, bibelots, souvenirs, etc. Por outro lado, a aproximação de Leonardo, artista da segunda metade do século XV com o presente, é muito significativa pois coloca-o no presente como personagem viva. $\mathrm{O}$ verso aves para lhes dar, de novo, asas é muito expressivo pois alude às várias tentativas de voar que Leonardo aperfeiçoou durante as suas experiências como engenheiro e, ao mesmo tempo, revela um estilo de escritura singular mas fluente.

O poeta termina a sua composição exprimindo dor e sofrimento quando exclama: Ó coisas ocres, de açafrão, enegrecidas; sente-se pois incomodado com as coisas vazias, pretas, escuras, acres. Apesar do sofrimento não abandona a esperança, mesmo que seja doada ou até oferecida por um rosto desconhecido, porque sempre é uma nesga de esperança. E assim:

[...] buscando pedaços de pão

Que transeuntes dadivosos oferecem.

E à espera que uma persiana se abra. 
Por fim, espera poder alcançar o tão desejado descanso e conforto que se poderá concretizar na simples presença de alguém que lhe recordará, obrigatoriamente, a mãe e que por isso naturalmente o acolherá. Na realidade, não importa quem seja.

Os dois poemas analisados apresentam uma figuração da cidade de Florença característica do estilo literário de Osório: é perceptível um amor/ódio vivido em relação a esta cidade, mesmo se considerada maravilhosa; é perfeitamente visível a personificação das raízes do poeta, das brincadeiras da infância, da ternura materna e da união familiar; além disso, é facilmente identificável a influência das leituras dos clássicos e dos mitos italianos nos seus textos. Tais elementos encontram a sua justificação e essência na Arte florentina - cheia de esplendor. A terminologia usada para escrever os poemas representa uma realidade que é modelada e transformada pela vivência do poeta. De facto, e apesar de todas as contrariedades e sofrimentos da vida, António Osório procura, como todos os homens, a felicidade e a serenidade interior.

Ousar entrar no íntimo do ser e na alma do poeta não é tarefa fácil mas faz parte daquele desafio que a crítica exige. Neste sentido, a palavra poética tem de ser acolhida de modo quase dogmático se bem que ela seja ao mesmo tempo revolucionária e interrogativa:

... a poesia é a restauração permanente da linguagem na sua função original de simbolização da totalidade sem cessar esquecida no uso quanto possível consciente desse mesmo movimento criador através do qual os homens transfiguram o tempo (e para começar o do seu presente pessoal e histórico) naquela esperança de eternidade de que precisam para não se tornarem hóspedes ou vítimas obscuras dele... ${ }^{17}$

Qualquer posição poética apresenta sem dúvida diversas visões, muitas vezes até contraditórias da sociedade e da vida, mas revela sempre a mesma crença no poder das palavras.

${ }^{17}$ Eduardo Lourenço, Tempo e poesia, Lisboa, Relógio d’Água Editora, 1987, p. 21 